\title{
Impact of the Egyptian summer season on oxidative stress biomarkers and some physiological parameters in crossbred cows and Egyptian buffaloes
}

\author{
Maha M. Hady, T. M. Melegy and Shaimaa R. Anwar
}

\author{
Department of Nutrition and Clinical Nutrition, Faculty of Veterinary Medicine, Cairo University, Giza-12211, Egypt. \\ Corresponding author: Shaimaa R. Anwar, e-mail: vetsh.sr@gmail.com \\ Co-authors: MM: mhhady@yahoo.com,TM: tareqmoustapha@gmail.com \\ Received: 13-01-2018, Accepted: 02-05-2018, Published online: 08-06-2018
}

doi: 10.14202/vetworld.2018.771-777 How to cite this article: Hady MM, Melegy TM, Anwar SR (2018) Impact of the Egyptian summer season on oxidative stress biomarkers and some physiological parameters in crossbred cows and Egyptian buffaloes, Veterinary World, 11(6): 771-777.

\begin{abstract}
Aim: The current study aimed to compare the impact of heat stress (HS) on some physiological functions and blood oxidative stress biomarkers between dry dairy crossbred (Balady X Friesian) cows and buffaloes during Egyptian summer season (July-September).

Materials and Methods: A total of 26 healthy animals were equally used in the in the current study. The criterion for cows and buffaloes selection and the management conditions were similar. A total mixed ration to meet the animal's requirements was used, and dry matter intake (DMI) was calculated. Ambient temperature, relative humidity, temperature humidity index (THI), respiratory rate, and rectal temperature (RT) were daily recorded. Meanwhile, live body weight and body condition score were weekly recorded. Blood samples were collected bi-weekly, and plasma samples were harvested for malondialdehyde (MDA) content and enzymatic antioxidants such as glutathione peroxidase, superoxide dismutase, and catalase activities determinations throughout the experimental period ( 8 weeks - prepartum).

Results: The results confirmed, the HS condition, as the THI values ranged from 79.74 to 90.4 throughout the experimental period. In both species, HS increased RT and decreased DMI $(<10.5 \mathrm{~kg} /$ day and $9.5 \mathrm{~kg} /$ day in cows and buffaloes, respectively). Buffaloes seemed to be more affected by the hostile environmental condition of this study compared with their respective cows. Buffaloes had recorded up to $1{ }^{\circ} \mathrm{C}$ increase in their RTs in most of the point's period compared to cows. There was a continuous increase in MDA values (194.7 and $208.4 \mathrm{nmol} / \mathrm{gHb}$ in buffaloes and cows, respectively, 2 weeks prepartum) as the animals come close to parturition with moderate decrements for the enzymatic antioxidant activities in both cows and buffaloes.
\end{abstract}

Conclusion: It can be concluded that during Egyptian's summer season, HS had adversely affected feed intake and consequently animal's production performances.

Keywords: buffaloes, dairy cows, Egyptian's summer, heat stress, oxidative stress.

\section{Introduction}

In general, Egypt's summer is characterized by high ambient temperature and relative humidity (RH) which results in heat stress (HS) that ubiquitously affects the productive performance of livestock species. Oxidative stress (OS) is an increase in the generation of reactive oxygen species (ROS) more than the ability of the body antioxidant physiological mechanisms to do safe neutralization.

The earth's climate has been predicted to change continuously at exceptional rates in recent decades [1]. Summer temperature in the Mediterranean region, including Egypt is generally outside of the cow's

\footnotetext{
Copyright: Hady, et al. Open Access. This article is distributed under the terms of the Creative Commons Attribution 4.0 International License (http://creativecommons.org/licenses/by/4.0/), which permits unrestricted use, distribution, and reproduction in any medium, provided you give appropriate credit to the original author(s) and the source, provide a link to the Creative Commons license, and indicate if changes were made. The Creative Commons Public Domain Dedication waiver (http://creativecommons.org/ publicdomain/zero/1.0/) applies to the data made available in this article, unless otherwise stated.
}

"comfort zone" resulting in HS. The term HS is defined as the sum of heat accumulated from the environment and the failure of the animal to dissipate heat, which is mostly associated with a malfunction of the animal's productive and/or physiological metabolic process [2]. Acute and chronic HSs exhibit different responses on animal's production and metabolism. Temperature humidity index (THI) is a suitable measure to estimate HS in dairy cows [3]. It was suggested that THI can be classified into mild (72-80), severe (80-85), and deadly stress zones $(>85)$ [4]. Increasing air temperature and the temperature-humidity index are accompanied by rising rectal temperature (RT) above critical thresholds which are related to a decrease in dry matter intake (DMI), milk yield, and reduced milk yield efficiency in dairy cows [5]. The magnitude of the animal's response to elevated ambient temperatures depends on livestock species and their physiological state. Some species are reported to be the best tolerant to HS, namely goats [6], while pregnant and lactating ruminants are more susceptible to HS than non-pregnant and non-lactating ones. Glandular surface of sweat gland per $\mathrm{cm}^{2}$ of skin 
surface was 1.07 and 3.08 in cattle and that the skin thickness of buffaloes was about twice that of cattle, in Egyptian buffaloes [7]. The sweat glands in buffaloes are underdeveloped; this indicates that buffaloes have more poor heat tolerance than cattle (fewer sweat glands and black colored skin) and thus assigning buffaloes to be of reduced capacity to withstand HS and so need greater alertness to compete for such hostile condition [8]. Furthermore, HS is one of the wide varieties of factors which cause OS in vivo. OS results from increased production of free radicals and ROS, and a decrease in antioxidant defense mechanisms [9]. The majority of the studies dealing with the effects of HS on OS biomarkers (cellular and molecular) response have been conducted in circumstances that sustained moderate to severe HS under strictly defined experimental conditions (environmentally controlled chambers) on selected high yielding and intensively managed dairy cattle. Scarce studies are available for the effect of moderate to severe HS on OS biomarkers (OSB) of dairy cows and buffaloes raised under Egyptian summer environmental conditions.

Therefore, the current study was planned to compare the impact of HS of the Egyptian summer conditions on some metabolic aspects and OSB of dairy cows and Egyptian buffaloes of moderate production.

\section{Materials and Methods}

\section{Ethical approval}

Care and management of experimental animals were done according to the guidelines of the animal care committee (CU-II-F-16-18) Cairo University.

\section{Animals, ration, and experimental design}

A total of 26 healthy, mature animals (13 of crossbred Balady X Friesian cows and 13 Egyptian buffaloes) were equally distributed on the basis of multiparity (3-5 calving), expected calving date, previous lactation yield, body weight (BW), and body condition score (BCS 3.5-4.2) to an experimental trial during the dry period (8 weeks pre-parturient). Experimental animal's average BW was $625 \pm 25 \mathrm{~kg}$ and the average fat-corrected milk (FCM) containing 4\% fat was $19.40 \pm 2 \mathrm{~kg}$ for cows and $21.30 \pm 2 \mathrm{~kg}$ for buffaloes. FCM was calculated using the following equation: $\mathrm{FCM}=0.4 *$ amount of milk $+15 *$ amount of fat [10]. Experimental animals were raised at a private farm in the Nobaria province during the period of the summer season (JulySeptember). Animals were housed in shaded loose pens with adjacent outside yards supplied with evaporative mist and fan systems. The experimental animals were fed on commercially available total mixed ration. Clean water was supplied all the time. Daily DMI was recorded. The ingredients and calculated analyses of the ration are summarized in Table-1.

\section{Measurements and sampling}

\section{Environmental temperature and humidity}

Digital hygrometer-thermometer device was daily used for measuring RH and temperature (at
Table-1: Ingredients, nutrient's composition, and calculated analysis of experimental ration.

\begin{tabular}{lc}
\hline Experimental ration (8 weeks prepartum) & \% DM \\
\hline Ingredient & DM \\
Corn silage & 17.5 \\
Beet sugar pulp & 9.5 \\
Yellow corn & 18.4 \\
SBM (44\%) & 10.2 \\
Berseem hay & 40.7 \\
Salt & 0.54 \\
Sodium bicarbonate & 1.00 \\
Limestone & 0.68 \\
Calcium phosphate (monobasic) & 0.50 \\
Magnesium oxide & 0.35 \\
Premix* & 0.13 \\
Calcium bentonite & 0.50 \\
Total & 100 \\
Calculated analysis & \\
NE $($ Mcal/kg) & 1.28 \\
CP (\% DM) & 12.8 \\
Forage NDF (\% DM) & 32.61 \\
Ether-extract (\% DM) & 2.10 \\
RUP (\% CP) & 33.45 \\
Ca (\% DM) & 0.90 \\
P (\% DM) & 0.37 \\
\hline
\end{tabular}

*Contained $20.0 \% \mathrm{Cl}, 13.0 \% \mathrm{Na}, 10.0 \% \mathrm{Ca}, 8.0 \% \mathrm{Mg}$, $8.0 \% \mathrm{~S}, 1.0 \% \mathrm{~K}, 0.62 \% \mathrm{Zn}, 0.54 \% \mathrm{Mn}, 0.20 \% \mathrm{Fe}$, $0.08 \% \mathrm{Cu}, 0.07 \% \mathrm{I}$ and $0.2 \% \mathrm{Co}, 551 \mathrm{IU} / \mathrm{g}$ Vitamin A, $132 \mathrm{IU} / \mathrm{g}$ Vitamin $\mathrm{D}, 3 \mathrm{IU} / \mathrm{g}$ Vitamin $\mathrm{E} \mathrm{NE}_{1}=$ Net energy for lactation, $\mathrm{CP}=$ Crude protein, $\mathrm{NDF}=$ Neutral detergent fiber, $\mathrm{RUP}=$ Rumen un-degradable protein, $\mathrm{DM}=$ Dry matter

0600,1200 , and $1800 \mathrm{~h}$ ) at a fixed time. THI was calculated according to Thatcher et al. [11].

\section{Animal temperature and respiratory rate}

RTs and respiratory rates were obtained twice daily (at 0600 and $1600 \mathrm{~h}$ ) with a digital rectal thermometer and visual counting flank movements during a $15 \mathrm{~S}$. interval and then multiplied by 4 .

\section{Live $B W$ and $B C S$}

BWs and BCS measurements were done weekly by the same technician for all animals immediately at morning and before feeding.

\section{Blood sampling and analysis}

Bi-weekly blood samples were collected from all animals (cows and buffaloes) during the 8 weeks prepartum-2 weeks prepartum. All blood samples were collected from the coccygeal blood vessel then placed into $10-\mathrm{mL}$ heparin Vacutainers. After proper centrifugation, the plasma samples were harvested and decanted into $1.5 \mathrm{~mL}$ aliquots and stored at $-20^{\circ} \mathrm{C}$ until further analyses. Measuring OSB activity was determined through measuring plasma malondialdehyde (MDA) content, plasma glutathione peroxidase (GPX), catalase (CAT), and superoxide dismutase (SOD) activities using diagnostic kits supplied by Biodiagnostic ${ }^{\circledR}$ Company, Egypt. Plasma MDA content was determined according to the method of Draper and Hadley [12], and plasma GPX activity was estimated as described by Lin et al. [13]. CAT and 
SOD activities in erythrocyte were determined calorimetrically by the methods described by Goth [14].

\section{Statistical analysis}

Statistical analysis of the data was assessed using Minitab 17.0 ${ }^{\circledR}$ statistical program [15]. Student's t-test for independent groups was done. Significance was considered at $p \leq 0.05$ levels. Pearson correlation analysis between the effect of cows and buffaloes RT and DMI was also computed. In addition to that, predicted DMI in cows and buffaloes was obtained in relation to RT using line fit plot and regression equation. The significance of difference was based on the probability of a Type I error set at $\mathrm{p} \leq 0.05$.

\section{Results and Discussion}

The results of ambient temperature $(\mathrm{T})\left({ }^{\circ} \mathrm{C}\right), \mathrm{RH}$ and THI measurements throughout 8 weeks prepartum are presented in Table- 2 . The presented data revealed that the THI indices during the experimental period which lasted from July to September had reached the maximum 89.1 and 90.4 in the last 3 weeks prepartum. However, at all the times of the experimental period (Egyptian summer climate), the THI had reached more than 80 except for the $1^{\text {st }}$ week of the study (79.74). THI could be used as an indicator of thermal climate as indicated by Akyuz et al. [16]. According to Thatcher et al., lactating cows are thought to experience no stress when THI is $<72$ and severe stress when THI exceeds 88 [11]. For each $10 \mathrm{~L}$ milk yield per day, metabolizable energy requirements of cows are roughly doubled, and nearly $35 \%$ of this energy is dissipated as heat [17]. Hence, high yielding cows suffer more than lower yielding ones, because the upper critical temperature shifts downward as milk production, feed intake, and heat production increases [18]. Nevertheless, buffaloes have been reported to be more susceptible to HS than cows, as the increase in temperature causes stress due to increased body heat loading and the low potentiality to dissipate heat from the body surface due to fewer and ill-developed sweat glands as well as black colored skin [19]. THI values more than 72 are considered stressful, and THI over 78 is recognized as very severe HS to buffaloes [20]. The degree to which an animal resists change in body temperature varies in different species because of differences in their heat-regulating mechanisms [21].

RT is a reliable tool to determine animal's temperature followed by ambient temperature. The results of the impact of Egyptian summer conditions on RTs and respiratory rates of cows and buffaloes during 8 weeks prepartum are presented in Table-3. The results demonstrated that there was no significant difference between species, although both cows and buffaloes were severely affected by HS as the recorded RT values were higher than normal values in the thermoneutral periods. However, buffaloes seemed to be more affected by the hostile environmental condition of this study compared with their respective
Table-2: Average atmospheric temperature $\left({ }^{\circ} \mathrm{C}\right), \mathrm{RH}(\%)$, and THI during 8-week prepartum (July-September).

\begin{tabular}{lccc}
\hline Weeks prepartum & $\mathbf{T}$ & $\mathbf{R H}$ & THI \\
\hline 8 & 31.6 & 50.2 & 79.74 \\
7 & 36.2 & 50 & 85.9 \\
6 & 37.4 & 51.2 & 87.1 \\
5 & 37.8 & 49.8 & 87.9 \\
4 & 38.4 & 49.7 & 88.8 \\
3 & 39.1 & 52.4 & 89.1 \\
2 & 38.7 & 50.2 & 89.1 \\
1 & 39.7 & 51.2 & 90.4 \\
Average & 37.7 & 50.2 & 87.2 \\
\hline
\end{tabular}

$\mathrm{RH}=$ Relative humidity, $\mathrm{THI}=$ Temperature humidity index

Table-3: Average weekly $\mathrm{RT}\left({ }^{\circ} \mathrm{C}\right)$ and respiratory rate (breaths/min) of experimental animals during the dry period ( 8 weeks prepartum).

\begin{tabular}{lccccc}
\hline Weeks prepartum & \multicolumn{2}{c}{ RT } & & \multicolumn{2}{c}{ Respiratory rate } \\
\cline { 2 - 3 } \cline { 5 - 6 } & Cow & Buffalo & & Cow & Buffalo \\
\hline 8 & 39.1 & 40.5 & & 70.5 & 71.8 \\
7 & 38.7 & 39.8 & & 69.5 & 68.7 \\
6 & 38.5 & 38.7 & & 63.4 & 62.8 \\
5 & 39.2 & 40.3 & & 67.4 & 67.2 \\
4 & 39.4 & 40.8 & & 67.8 & 68.1 \\
3 & 38.7 & 40.2 & & 65.2 & 66.4 \\
2 & 39.8 & 40.7 & 67.9 & 68.4 \\
1 & 40.1 & 41.1 & 71.8 & 72.6 \\
t-value & 0.88 & 1.07 & 2.41 & 3.73 \\
Significance & NS & NS & NS & NS \\
\hline
\end{tabular}

$\mathrm{NS}=$ Non-significant at $\mathrm{P}>0.05$. RT $=$ Rectal temperature

cows. Buffaloes had recorded up to $1{ }^{\circ} \mathrm{C}$ increase in their RTs in most of the point's period compared to cows. Similarly, Joshi and Tripathy recorded a $2.6^{\circ} \mathrm{C}$ rise in RT in buffalo's calves when exposed to direct sun rays in the months of June and July [22] Air temperature $\left(13-18^{\circ} \mathrm{C}\right), \mathrm{RH}(55-65 \%)$, and wind velocity $(5-8 \mathrm{~km} / \mathrm{h})$ are the optimum conditions for buffaloes and the THI $\geq 77$ is very stressful [20]. On the contrary, Mullick reported that RT during the summer months under high and low humidity conditions was always less for buffaloes than cattle [23]. Singh et al. found that HS had a detrimental effect on lactation length, calving interval, milk constituents, and milk yield in Murrah buffaloes [24]. The relationship between THI as a measure of HS and animal RT (Figure-1) demonstrated that at the peak of severe HS, the THI was 89.1 and 90.4 attended during the last 3 weeks prepartum. Rectal body temperature is a sensitive indicator of physiological response to HS as it is nearly constant under normal conditions [25]. Regarding the respiratory rate (Table-3), there was no significant difference between species and both species attended the highest respiratory rates in the last week prepartum which is compatible with the results of THI and RT. HS significantly affected respiratory rate (breaths $/ \mathrm{min}$ ) when compared to normal values (76.8 and 77.8 vs. $40-50)$ for cow and buffalo, respectively, as presented by Das et al. [26]. According to Dalcin et al., respiratory rate can be a relevant physiological indicator for HS [27]. 
A higher respiratory rate of $71.5 / \mathrm{min}$ during summer compared to $38.8 / \mathrm{min}$ in the winter was recorded in lactating cows by Silanikove [18]. Respiratory rate is an indicator of HS in the hot environment [27]. The normal respiratory rate is approximately $10-30$ breaths/min [7]. There is a very high positive correlation between the respiratory rate and ambient temperature. The increase in breathing rate (panting) sharply increases the loss of $\mathrm{CO}_{2}$ through pulmonary ventilation with upsetting the critical balance of carbonic acid to bicarbonate excretion causing respiratory alkalosis [26]. In cattle under heat load, about $15 \%$ of the endogenous heat is lost directly from the body core through the respiratory tract [28]. HS that is characterized by elevated respiratory rates and RTs has been implicated in impaired metabolism and in poor reproductive performance in dairy cattle as well as in dairy buffaloes [26,29] independent of any effects on feed intake. The results of regression analysis between cows and buffaloes RTs and DMIs are presented in Figures-2 and 3, respectively. Predicted DMIs in cows and buffaloes were obtained in relation to RT using the following models: $y=-0.7624 x+41.057$ and $y=-0.9195 x+46.972$, respectively. Where: $y=$ variable measured (DMI) and $\mathrm{x}=\mathrm{RT}$ taking into account that the following models are applied when RT as well as THI from 38 to $41^{\circ} \mathrm{C}$ and $79-90$, respectively. In addition, the regression coefficient for buffaloes and cows is -0.9195 and -0.9196 , respectively. It was also noticed that with the increase in the RT there was a decrease in the DMI in both species. The increase of the RTs of the cows over $40^{\circ} \mathrm{C}$ was associated with a dramatic decrease in the DMI to $<10.5 \mathrm{~kg}$ /day. However, buffaloes demonstrated higher RTs, especially in the last week prepartum which was associated with a DMI drop to $<9.5 \mathrm{~kg} /$ day. The significant negative correlation between animal's RT and its DMI was previously reported in Holsteins [25]. According to Rhoads et al., feed intake started to decrease at air temperatures of $25-26^{\circ} \mathrm{C}$ in dairy cows and dramatically declined above $30^{\circ} \mathrm{C}$ in moderate climatic condition and at $40^{\circ} \mathrm{C}$ [30], it may decrease by as much as $40 \%$. Moreover, the same correlation was demonstrated in buffaloes as up to $40 \%$ reduction in voluntary DMI during the summer months was recorded as compared to the amount consumed during the cooler months [31]. Feed intake reduction due to the increase in temperature might be attributed to several reasons, among them the direct effect of elevated temperature on the appetite center in the hypothalamus

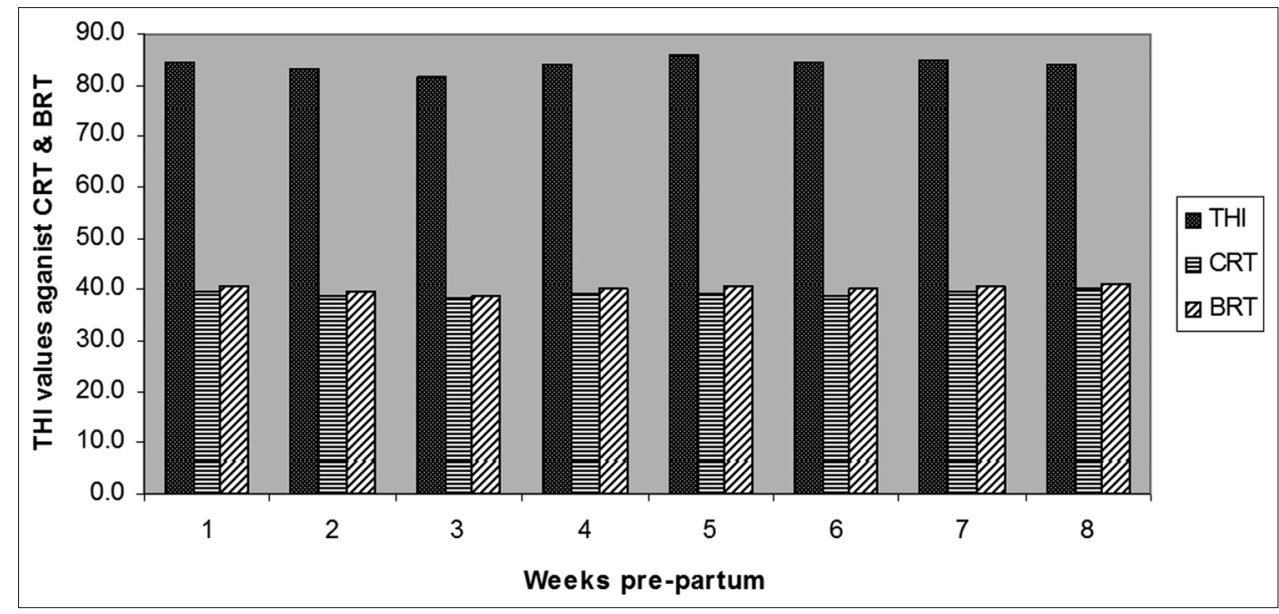

Figure-1: Impact of temperature humidity index on cows and buffaloes rectal temperature $\left({ }^{\circ} \mathrm{C}\right)$.

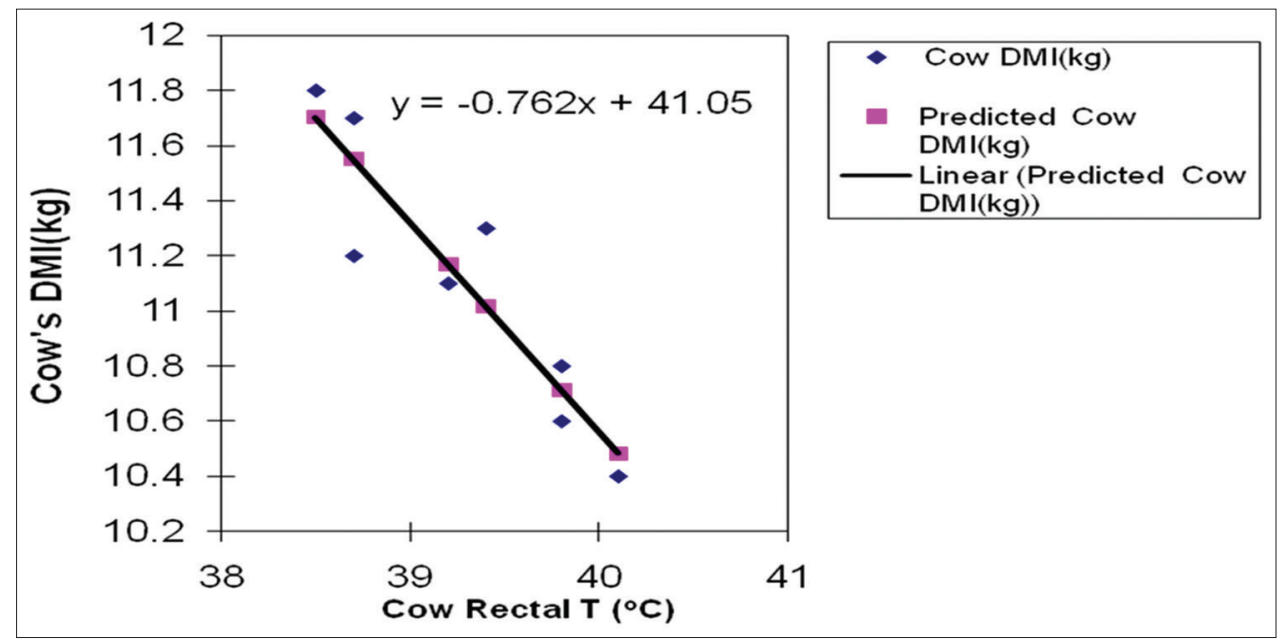

Figure-2: Regression analysis between cow rectal temperature $\left({ }^{\circ} \mathrm{C}\right)$ and dry matter intake $(\mathrm{kg})$. 
through increasing leptin and adiponectin hormones levels [32], resulting in reduction of the production of volatile fatty acids which are the main energy source in ruminants [33]. Feed intake reduction can also occur as a result of the inverse relationship between DMI and non esterified fatty acids concentrations during the peri-parturient period [34].

The results of the impact of HS on OSB of dry cows and buffaloes are presented in Table-4. It was observed that the values of MDA (nmol/gHb) as an indicator of OS ranged from 112.12 to 194.7 and from 125.87 to 208.4 in cows and buffaloes, respectively, during the 8 weeks prepartum period. There was an insignificant difference between species; however, buffaloes exhibited the highest values, especially in the last 2 weeks prepartum. Moreover, the MDA content in both species demonstrated marked increase toward the calving date ( 2 weeks prepartum) as the metabolic load increased. Mitochondrial membrane constituents are particularly susceptible to oxidative damage by ROS. Phospholipid constituents of the mitochondrial membranes are rich in unsaturated fatty acids which are susceptible to the attack by oxygen radical, due to the presence of double bonds, which undertake peroxidation through a chain of oxidative reactions [35]. MDA is an end product due to polyunsaturated fatty

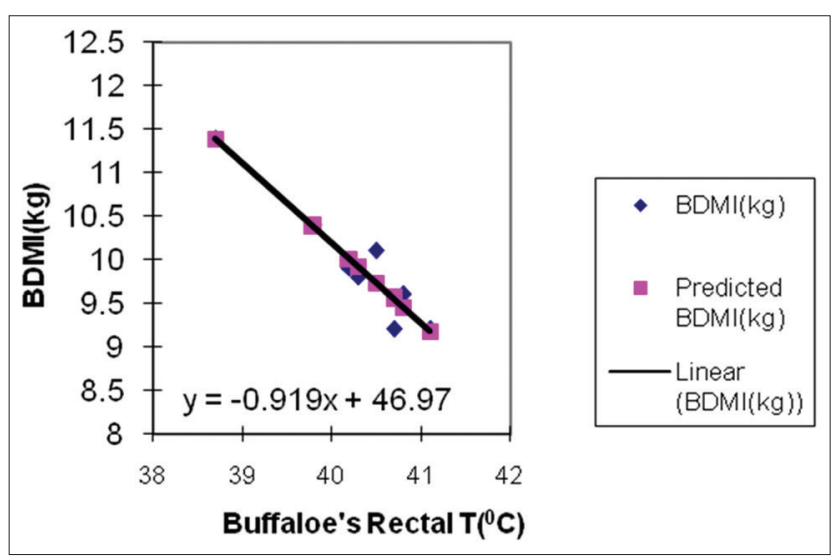

Figure-3: Regression analysis between buffaloes rectal temperature and dry matter intake. acid peroxidation. High plasmatic MDA levels occur due to HS [36].

These results indicate that despite the metabolic stress that occurred in the pregnant dry animals which were aggravated by the HS; it could adjust to the environment by secreting large quantities of cortisol [24]. Higher concentration of this catabolic hormone normally results in lipolysis, and adipose mobilization in heat stressed cows to initiate and maintain milk production [37]. Similar to our results, several studies demonstrated that the MDA content increased around calving $[38,39]$.

The results of the enzymatic antioxidant capacity of dry cows and buffaloes during summer season (Table-4) revealed that there was an insignificant difference between species except for the GPX starting from 6 weeks prepartum. One can observe that as the animals come near to calving time, the levels of the enzymatic antioxidants exhibited modest instable decrements. The average values recorded for GPX, SOD, and CAT in cows and buffaloes are within the values recorded by other studies $[40,41]$, respectively. The modest decrease in the enzymatic antioxidant activity was in harmony with the confirmed HS condition observed in the current study. Megahed et al. examined the effects of HS in Egyptian buffaloes in summer and winter seasons and reported that SOD activities were significantly lower in the summer as compared to the winter season [41]. On the contrary, some authors demonstrated a significant increase in SOD and CAT in buffaloes [42] and cattle [38] during summer compared to the spring season. The enzymatic antioxidants, mostly metalloenzymes are the first line of a defense system that counteracts the oxidative damage of the intracellular constituents induced by ROS [26]. The discrepancy of the enzymatic antioxidant activity results might be attributed to multi-factors at these particular points among them: The physiological status of the animal (heifer, dry, or first trimester of milk production); type of HS (experimental chambers vs. field situation) as well as the methodology used. One possible explanation that both species were subjected

Table-4: Different stress biomarkers of cows and buffaloes during Egyptian summer at different weeks prepartum.

\begin{tabular}{|c|c|c|c|c|c|c|c|c|}
\hline \multirow[t]{3}{*}{ Species } & \multicolumn{8}{|c|}{ Weeks prepartum } \\
\hline & \multicolumn{4}{|c|}{8} & \multicolumn{4}{|c|}{6} \\
\hline & MDA & GPX & SOD & CAT & MDA & GPX & SOD & CAT \\
\hline Cow & $112.23 \pm 10.4$ & $38.14 \pm 1.1$ & $6.25 \pm 0.52$ & $26.71 \pm 2.4$ & $123.4 \pm 8.47$ & $37.65 \pm 2.1^{a}$ & $7.14 \pm 0.81$ & $26.14 \pm 3.10^{a}$ \\
\hline Buffalo & $125.87 \pm 8.6$ & $32.62 \pm 1.8$ & $7.48 \pm 0.64$ & $25.63 \pm 1.4$ & $132.33 \pm 9.7$ & $30.41 \pm 1.4^{\mathrm{b}}$ & $6.85 \pm 0.52$ & $22.27 \pm 1.9$ \\
\hline \multirow[t]{3}{*}{ Species } & \multicolumn{8}{|c|}{ Weeks prepartum } \\
\hline & \multicolumn{4}{|c|}{4} & \multicolumn{4}{|c|}{2} \\
\hline & MDA & GPX & SOD & CAT & MDA & GPX & SOD & CAT \\
\hline Cow & $165.84 \pm 9.7$ & $29.4 \pm 1.1^{\mathrm{a}}$ & $5.11 \pm 0.51$ & $21.3 \pm 2.6$ & $194.7 \pm 17.2^{\mathrm{a}}$ & $28.7 \pm 1.8^{\mathrm{a}}$ & $3.49 \pm 0.42$ & $18.41 \pm 1.7$ \\
\hline Buffalo & $185.61 \pm 10.2^{\mathrm{a}}$ & $25.7 \pm 0.7^{b}$ & $4.48 \pm 0.32$ & $18.6 \pm 1.9$ & $208.4 \pm 16.4$ & $22.9 \pm 1.3^{b}$ & $3.56 \pm 0.51$ & $14.31 \pm 1.32$ \\
\hline
\end{tabular}

Designation of the values of MDA as $\mathrm{nmol} / \mathrm{gHb}, \mathrm{GPX}$ as $\mathrm{mol} / \mathrm{mg} \mathrm{Hb}$ and SOD and CAT as $\mathrm{U} / \mathrm{mg} \mathrm{Hb}$, values with different superscripts at the same column significantly differ at $\mathrm{P}<0.05$. GPX=Glutathione peroxidase, MDA=Malondialdehyde, SOD $=$ Superoxide dismutase, CAT=Catalase 
to long-term HS at stressful metabolic and physiological status (dried pregnant animals) which was accompanied by marked reduction in DMI. This reduction in DMI (low nutrients and antioxidant intakes) plus persisting secretion of catabolic cortisol to satisfy energy needs had resulted in lipolysis, which eventually increased the production of free radicals and ROS and exhausted the antioxidant defenses.

\section{Conclusion}

It is to be concluded that the Egyptian summer environmental condition is incriminated for HS and using THI is a good indicator. As high yielding animals, moderate yielders are also affected by HS. RT and DMI are highly correlated to HS. Dairy buffaloes seem to be more affected by HS than cows. As the field of OS in ruminant medicine is still in the early stages, the results of OS biomarkers furnish a base for such data, especially for buffaloes. An effective nutritional strategy by supplying surplus antioxidants to the ration of heat-stressed animal is a smart and effective promising path to alleviate metabolic, environmental heat loads.

\section{Authors' Contributions}

MM contributed in the design of the work, data collection, and analysis, interpretation, drafting the article, revision, and final approval of the article to be published. TM contributed to the design of the work, data analysis and final approval of the article to be published. SRA helped in interpretation of the data, drafting the article, revision and final approval of the article to be published. All authors read and approved the final manuscript.

\section{Acknowledgments}

The authors are grateful to the owners of the private farm at Nobaria province for their support during the experimental trial. The present study received no financial support.

\section{Competing Interests}

The authors declare that they have no competing interests.

\section{References}

1. IPCC. (2007) The Intergovernmental Panel on Climate Change $4^{\text {th }}$ Assessment. A Report. Available from: http:// www.ipcc.ch. Last accessed on 12-02-2018.

2. Bernabucci, U. and Mele, M. (2014) Effect of heat stress on animal production and welfare: The case of a dairy cow. Agrochimica, 58: 53-60.

3. Soumya, D., Chakravarty, A.K., Avtar, S., Arpan, U., Manvendra, S. and Saleem, Y. (2016) Effect of heat stress on reproductive performances of dairy cattle and buffaloes: A review. Vet World, 9(3): 235-244.

4. Kohli, S, Atheya, U.K. and Thapliyal, A. (2014) Assessment of optimum thermal humidity index for crossbred dairy cows in Dehradun district, Uttarakhand, India. Vet World, 7(11): 916-921.

5. Lamp, O., Derno, M., Otten, W., Mielenz, M., Nurnberg, G. and Kuhla, B. (2015) Metabolic heat stress adaptation in transition cows: Differences in macronutrient oxidation between late-gestating and early-lactating German Holstein dairy cows. PLoS One, 10(5): e0125264.

6. Gupta, M., Kumar, S. and Dangi, S.S. (2013) Physiological, biochemical and molecular responses to thermal stress in goats. Int. J. Livest. Res., 2: 27.

7. Hafez, E.S.E., Badreldin, A.L. and Shafie, M.M. (1955) Skin structure of Egyptian buffalo particular reference to sweat gland. J. Agric. Sci., 46: 19-30.

8. Vo, T.K.T. and Wang, S.C. (2007) Differences in adaptation to tropical weather between buffaloes and cattle. Ital. $J$. Anim. Sci., 6(2): 1340-1343.

9. Trevisan, M., Browne, R., Ram, M., Muti, P., Freudenheim, J.A., Carosella, M. and Armstrong, D. (2001) Correlates of markers of oxidative status in the general population. Am. J. Epidemiol., 154: 348-356.

10. National Research Council. (2001) Nutrient Requirements of Dairy Cattle. $7^{\text {th }}$ ed. National Research Council, Washington, DC.

11. Thatcher, W.W., Flamenbaum, I., Block, J. and Bilby, T.R (2010) Interrelationships of Heat Stress and Reproduction in Lactating Dairy Cows. High Plains Dairy Conference. p45-60.

12. Draper, H. and. Hadley, M. (1990) Malondialdehyde determination as index of lipid peroxidation. Methods Enzymol., 186: 421-431.

13. Lin, H.M., Dillard, C.J. and Tappel, A.L. (1988) Plasma SH and GSH measurements. Methods Enzymol., 233: 380-382.

14. Goth, L. (1991) A simple method for determination of serum catalase activity and revision of reference range. Clin. Chim. Acta, 196: 143-152.

15. Minitab 17 Statistical Software. (2010) (Computer Software). State College. PA: Minitab Inc. Available from: http://www.Minitab.com. Last accessed on 23-12-2017.

16. Akyuz, A., Boyaci, S. and Cayli A. (2010) Determination of critical period for dairy cows using thermal humidity index. J. Anim. Vet. Adv., 9(13): 1824-1827.

17. Kadzere, C.T., Murphy, M.R., SilLanIkove, N. and Maltz, E. (2002) Heat stress in lactating dairy cows: A review. Livest. Prod. Sci., 77: 59-91.

18. Silanikove, N. (2000) Effect of heat stress on the welfare of extensively managed domestic ruminants. Livest. Sci., 84: 671.

19. Koga, A., Chikamune, T., Kanai, Y., Homma, H., Tajima, A., Ishikawa, N., Furukawa, R., Ueno, T., Nakajima, M. and Watanabe, T. (1999) Effects of high environmental temperatures on some physicochemical parameters of blood and heat production in swamp buffaloes and Holstein cattle. J. Anim. Sci., 62: 1022-1028.

20. Payne, W.J.A. (1990) An Introduction to Animal Husbandry in the Tropics. Longman Scientific and Technical, England.

21. Salah, M.S., Al Shaikh, M.A., Al Saiadi, M.Y. and Mogawer, H.H. (1995) Effect of prolactin inhibition on thermoregulation, water and food intake in heat stressed fat-tailed male lambs. J. Anim. Sci., 60: 87-91.

22. Joshi, B.C. and Tripathy, K.C. (1991) Heat stress effect on weight gain and related physiological responses of buffalo calves. J. Vet. Phys. Alli. Sci., 10: 43-48.

23. Mullick, D.N. (1959) A study on the metabolism of food nutrients in cattle and buffalo bulls under climatic stress. Indian J. Phys. Anim. Sci., 13: 107.

24. Singh, M., Chaudhari, B.K., Singh, J.K., Singh, A.K. and Maurya, P.K. (2013) Effects of thermal load on buffalo reproductive performance during the summer season. $J$. Bio. Sci., 1(1): 1-8.

25. Rejeb, M., Sadraoui, R., Najar, T. and Mrad, M.B. (2016) A complex interrelationship between rectal temperature and dairy cows' performance under heat stress conditions. Open. J. Anim. Sci., 5: 24-30.

26. Das, R., Sailo, L.N., Bharti, P., Saikia, J., Imtiwati, and Kumar, R. (2016) Impact of heat stress on health and performance of dairy animals: A review. Vet World, 9(3): 260-268. 
27. Dalcin, V.C., Fischer, V.D., Darlene, S.A., Evelyn, P.M., Stumpf, M.T., Kolling, G.J., Silva, M.V., Gualberto, B. and McManus, C. (2016) Physiological parameters for thermal stress in dairy cattle. R. Bras Zootec, 45(8): 458-465.

28. McDowell, R.E., Hooven, N.W and Camoens, J.K. (1976) Effects of climate on performance of Holsteins in first lactation. J. Dairy Sci., 59: 965-971.

29. Dash, S., Chakravarty, A.K., Singh, A., Upadhyay, A., Singh, M. and Yousuf, S. (2016) Effect of heat stress on reproductive performances of dairy cattle and buffaloes: A review. Vet World, 9(3): 235-244.

30. Rhoads, R.P., Baumgard, L.H., Suagee, J.K. and Sanders, S.R. (2013) Nutritional interventions to alleviate the negative consequences of heat stress. Adv. Nutr., 4(3): 267-276.

31. Ashour, G., Omran, F.I, Yousef, M.M and Shafie, M.M. (2007) Effect of thermal environment on water and feed intakes in relationship with growth of buffalo calves. Egypt. J. Anim. Prod., 44(1): 25-33.

32. Belhadj, S.I., Najar, T., Ghram, A. and Abdrrabba, M. (2016) Heat stress effects on livestock: Molecular, cellular and metabolic aspects, a review. J. Anim. Physio. Anim. Nutri., 100: 401-412.

33. Baile, C.A. and Forbes, J.M. (1974) Control of feed intake and regulation of energy balance in ruminants. Physiol. Rev., 54: 160.

34. Overton T.R. and Waldron, M.R. (2004) Nutritional management of transition dairy cows: Strategies to optimize metabolic health. J. Dairy Sci., 87: 105-119.

35. Belhadj, S.I., Najar, T., Ghram, A., Dabbebi, H., Ben Mrad, M. and Abdrabbah, M. (2014) Reactive oxygen species, heat stress and oxidative-induced mitochondrial damage. A review. Int. J. Hyperthermia, 30(7): 513-523.

36. Mujahid, A., Pumford, N.R., Bottje, W., Nakagawa, K., Miyazawa, T. and Akiba, M. (2007) Mitochondrial oxidative damage in chicken skeletal muscle induced by acute heat stress. J. Poult. Sci., 44: 439-450.

37. Rhoads, M.L., Rhoads, R.P., VanBaale, M.J., Collier, R.J., Sanders, S.R., Weber, W.J., Crooker, B.A. and Baumgard, L.H. (2009) Effects of heat stress and plane of nutrition on lactating Holstein cows: I. Production, metabolism, and aspects of circulating somatotropin. J Dairy Sci, 92: 1986-1997.

38. Yatoo, M.I., Dimri, M. and Sharma, M.C. (2014) Seasonal changes in certain blood antioxidants in cattle and buffaloes. Indian J. Dairy Sci., 84(2): 173-176.

39. Lallawmkimi, M.C., Singh, S.V., Upadhyay, R.C. and De, S. (2013) Impact of vitamin supplementation on heat shock protein 72 and antioxidant enzymes in different stages of Murrah buffaloes during seasonal stress. Indian J. Anim. Sci., 83(9): 909-915.

40. Ganaie, A.H., Shanker, G., Bumla, N.A, Ghasura, R.S. and Mir, N.A. (2013) Biochemical and physiological changes during thermal stress in bovines. J. Vet. Sci. Technol., 4: 126.

41. Megahed, G.A., Anwar, M.M., Wasfy, S.I. and Hammadeh, M.E. (2008) Influence of heat stress on the cortisol and oxidant-antioxidant balance during oestrous phase in buffalo-cows (Bubalus bubalis): Thermo-protective role of antioxidant treatment. Reprod. Dom. Anim., 43: 672-677.

42. Allaam, A.M., Tamer, S.A. and Elkhatam, A.O (2014) Biochemical and circulating oxidative stress biomarkers in Egyptian buffaloes (Bubalus bubalis) infested by sarcoptic mange. Glob. Vet., 13(4): 656-661. 